\title{
Do nomadismo ao "ideocídio": o imaginário fenomenológico dos rolezinhos na pós- modernidade
}

\author{
Eduardo Portanova Barros ${ }^{1}$ \\ Ana Taís Martins Portanova Barros ${ }^{2}$
}

\begin{abstract}
Resumo: Este artigo procura situar os rolezinhos - jovens de periferia que se deslocam em grupos aos shoppings - dentro de uma leitura interdisciplinar baseada, primeiro, na ideia de nomadismo desenvolvida por Maffesoli (2001). Também veremos os rolezinhos, filosoficamente falando e nos apoiando em Nietzsche, como uma afronta ao "ideal ascético", o de uma necessidade de um objetivo. Além disso, traremos uma possível relação entre este panorama dos rolezinhos com a perspectiva daquilo que o antropólogo e cientista político indiano Arjun Appadurai (2009) denomina "ideocídio": um modo de vida considerado perigoso à ordem das coisas. A metodologia se baseia no caráter fenomenológico (aquilo que se dá a ver) dessa prática e na ideia de uma tradição compreensiva de matriz weberiana, no sentido de superar uma visão objetivista dos fenômenos sociais. Isso quer dizer: sem resolução ou acabamento. Trata-se, em suma, de ultrapassar um dualismo das imagens, ultrapassamento esse que reconhece, por outro lado, a configuração de um choque de antíteses.
\end{abstract}

Palavras-chave: imaginário; cotidiano; rolezinhos; pósmodernidade; trágico.

\begin{abstract}
This article seeks to place the rolezinhos - outskirts of young people moving in groups to malls - within an interdisciplinary reading based on the concept of nomadism developed by Maffesoli. We will also see the rolezinhos, philosophically speaking and supporting us in Nietzsche, as an affront to an "ascetic ideal" and the need for a goal. In addition, we bring a possible relationship between the rolezinhos and what the anthropologist and Indian political scientist Appadurai (2009) calls "ideocídio": a way of life considered dangerous to the order of things. The methodology is based on the phenomenological character of this practice and the idea of a comprehensive tradition of Weberian view, to overcome an objectivist vision of social phenomena. That is to say, without resolution or finish. This is, in short, to overcome a dualism of images, surpassing
\end{abstract}

1 Professor-pesquisador do Programa de Pós-Graduação em Ciências Sociais da Unisinos (PNPD/CAPES/PPGCS), pós-doutor pela Université de Paris V (Sorbonne) e pela Unisinos (PPGCS). E-mail: eduardoportanova@hotmail.com.

2 Professora do PPGCOM/UFRGS, pós-doutora em Filosofia da Imagem pela Universidade de Lyon III. E-mail: anataismartins@hotmail.com. 
the one that recognizes, on the other hand, the configuration of an antithesis of shock.

Keywords: imaginary; quotidian; rolezinhos; postmodernity; tragic.

Nietzsche, na terceira dissertação de "Genealogia da moral", criticava o que ele chamou de ideais ascéticos no homem: a necessidade de um objetivo (1998, p. 87). Não teríamos com esse pensamento nietzscheano um dos traços sociológicos que caracterizariam a socialidade dos chamados rolezinhos? Essa prática de dar "rolês" (vaguear), que nasce das conexões em redes sociais, por si só um sinal dos tempos pós-modernos (sem entrarmos aqui na discussão pontual dessa questão, isso porque já está embutida neste conteúdo axiomaticamente), tem gerado um desconforto (UOL, 2014), para dizer o mínimo. Mas um desconforto para quem, exatamente? Poderíamos, para início de discussão, nos apoiar no que Simmel (2006) aponta como o "trágico da Sociologia" - não muito diferente do trágico para Nietzsche (2002), que o caracteriza como a relação entre os elementos apolíneos e dionisíacos - como veremos nos rolezinhos. Para Simmel, o trágico é uma questão que não termina na síntese perfeitamente acabada: "O indivíduo pode possuir tantas qualidades aprimoradas, altamente desenvolvidas, cultivadas quantas quiser - mas é justamente por isso que tanto mais inverossímil será a igualdade” (2006, p. 47).

De acordo com Nietzsche (2002), que introduziu o tema da tragédia grega na filosofia dita polar (por remeter a polaridades), percebia-se nas tragédias gregas, em contraposição às práticas racionais apolíneas, uma forma de expressão dionisíaca (desregrada) relativa ao deus Dionísio: aquele que "[...] suporta as dores da individuação” (2002, p. 94). Os rolezinhos, fazendo uma analogia, representam antes o espírito dionisíaco, isso por causa de uma prática cotidiana espontânea em oposição ao espírito social apolíneo, que sugere a retidão, a verticalidade e, como vimos acima, a necessidade de um objetivo. Estes dois espíritos, segundo Nietzsche (2002), estão em constante guerra entre si. É, sim, um estado de permanente tensão. Essa tensão, usada aqui como uma referência epistemológica oriunda dos campos eletromagnéticos da Física, diz respeito a uma dinâmica de forças ou polaridades. 
Morin (1991), na sua teoria da complexidade, também se utiliza desse referencial, salientando as leis da termodinâmica para uma interpretação das socialidades pós-modernas. Percebeu que a irrupção, na ciência, do princípio da desordem na segunda lei da termodinâmica podia inspirar estudos de cunho sociológico. Neste segundo princípio - ao contrário do primeiro, no qual a energia se conserva - a energia sob a forma de calor se degrada, resultando na entropia. O que acontece no campo da física, de acordo com Morin, é semelhante à natureza de qualquer atividade humana. Não se trata de justificar a sociedade pelo princípio da entropia. Trata-se de uma ideia aproximativa pelo fato de que esse tecido conjuntivo complexo se opõe ao paradigma que tudo simplifica para expulsar a desordem no seio de sistemas organizados.

Toda a prática dos rolezinhos, portanto, apresenta, além de uma característica complexa e nômade (Maffesoli, 2001), e nômade tanto por romper fronteiras (aquelas que a sociedade da Razão lhes impõe) quanto por variar de espaço na cidade, a dinâmica das polaridades. $\mathrm{O}$ deslocamento se dá de várias formas, não só física, mas também "ideológica" (palavra um tanto desgastada hoje em dia). Quando o conjunto se fortalece, a presença dos rolezinhos em espaços coletivos, como nos shoppings centers, principalmente, passa a ser considerada uma ameaça. A questão sociológica dinâmica, sob o prisma maffesoliano, indica que, para além de uma concepção progressista, destacamse três arcaísmos na pós-modernidade: o retorno de Dionísio (dimensão hedonista da existência), a ideia de tribo (modo de estar-junto a partir do gosto compartilhado) e a de nomadismo (sedentarização da existência, retorno da animalidade, do bárbaro e do selvagem).

Contra o grande esquema que marcou a modernidade, o "enraizamento dinâmico", este dos rolezinhos, é uma energia que se mantém no aqui e agora. Diante disso, pergunta-se: até que ponto essa energia nos permitiria pensar em termos de um reencantamento do mundo? Quando Weber denuncia a racionalização exagerada da existência, nas duas primeiras décadas do século passado, e Nietzsche aparece como um dos pais fundadores da pósmodernidade, na opinião do filósofo italiano Gianni Vattimo (1996), de que forma estes fatores se situam no atual estado da cultura? Weber, em seu "Ensaio 
sobre algumas categorias da Sociologia Compreensiva" (1913), percebeu que era possível procurar a constituição de sentido sociológico por meio de atividades humanas - isto é, contra o psicologismo, o historicismo e o realismo.

Se no materialismo histórico o que conta são relações objetivas de produção, na tradição compreensiva importa antes as condições reflexivas do agir humano, do agir social, do agir comunitário, incluindo práticas afetivas desse agir. Maffesoli (2012) lembra a importância do imaginário enquanto matriz, e sublinha que, junto aos aspectos racionais e sociais, percebe-se a dimensão (stricto sensu) mítica. Conforme ele, para exemplificar, a monarquia moderna se explica como homogeneização do mundo, e é representada pelo número um. Mas, continua Maffesoli (1997), observa-se, há algum tempo, o que chama de "tribalismo contemporâneo": paixão comum e partilha de emoções. Esse tribalismo representa outra maneira de estar-junto, um estar-junto, como o próprio Maffesoli indica, à-toa, a exemplo, poderíamos nós dizer, dos rolezinhos.

Por isso, o sociólogo francês crê na pluralização (estar-junto) da pessoa acima do individualismo homogêneo, da mesma forma que o pluralismo "imaginal”, derivado de imaginário. Este termo não é sinônimo de fantasia ou ilusão, mas sim a característica de um trajeto antropológico no qual acontece, conforme Durand, uma incessante troca entre as pulsões subjetivas e assimiladoras e as intimações objetivas que emanam do meio cósmico e social. Prosseguindo com Durand (1997), é importante ressaltar que ele, Durand, apresenta três níveis constitutivos do ser humano. O primeiro é o "isso", caracterizado como o nível fundante ou fundador, de natureza arquetípica (o inconsciente antropológico). Depois vem o "ego societal", dividido em dois polos, o negativo (no qual poderíamos colocar todas as minorias sociais, os marginalizados, em outras palavras, incluindo os "rolezinhos") e o positivo (o ideário, para não dizer ideologia, vigente).

Um terceiro ponto é o "superego societal", que é a imagem racionalizada que uma sociedade tem de si e que, a partir do século XX, localiza-se, primordialmente, nos meios de comunicação de massa. São três níveis 
vitalizados por um "mito circulante" e é esse mito, o de Hermes (deus do comércio, da eloquência e das comunicações), que lhe dá sentido, segundo Teixeira Coelho (1997). Os símbolos que se organizam em variedades excludentes e antitéticas, como natureza-cultura, claro-obscuro, tendem, segundo a Teoria do Imaginário em Durand (1997), a se situar, coletivamente, como cargas positiva e negativa. É desse paradoxo inicial que irá se configurar a metafísica do Ocidente, postula a Teoria do Imaginário, exemplificando com o pensamento logocêntrico em Sócrates e Hegel.

Nietzsche (2006) afirma que Sócrates e Platão representavam o declínio e eram os instrumentos da dissolução grega. Ainda para Nietzsche, estes dois sábios tinham introduzido a racionalização no espírito mitológico grego. Essa "dobra" trouxe, na visão de Nietzsche, o "socratismo da moral", uma visão ascética da sociedade e também contrária aos instintos helenos mais antigos. Conforme Nietzsche (2006), Sócrates altera a fisionomia grega com a dialética, que não era comum antes dele. Com Nietzsche, entre outros autores, procuramos interpretar o sentido sociológico dinâmico no sentido de uma pouca nitidez das fronteiras, o processo - e processo é bem o termo - de aproximação dos conteúdos e a relativização do saber.

Se, em determinada época, a Sociologia superestimou a verdade, podemos afirmar, hoje, que não existem verdades absolutas e que o homem está longe de ser uma medida segura das coisas, uma vez que, aqui retomando Nietzsche (2006), o erro é a crença num ideal racionalista e cartesiano. Ao tentarmos reduzir todos os fenômenos sociológicos a uma causalidade única, como no positivismo ou no determinismo das ciências no século XIX, deixamos de ser complexos e acabamos na esterilidade figurativa. A sociedade sente esse momento como uma perda e acaba recalcando sua criação. O retorno é sempre trágico, tanto no sentido comum do termo quanto no sentido filosófico de luta das forças apolíneas e dionisíacas. Com a força apolínea, abre-se uma diferença, uma antinomia, um dualismo, uma fissura, um confronto, uma oposição na sociedade. Dionísio reequilibra a fisionomia desse museu imaginário, mas a guerra entre essas duas forças traz consequências das quais não escapamos, nem como indivíduos que somos, nem como coletividade em que nos situamos. 
Estamos longe da cura, mas nem por isso deixamos, por outro lado, de viver intensamente mesmo que seja um eterno instante ou uma verdade concreta, aqui remetendo ao pragmatismo simmeliano.

Appadurai (2009), a respeito desse aspecto ameaçador de um grupo, apresenta a noção de "ideocídio", uma ideologia do ódio, um ódio a minorias "internas" (2009, p. 88). "Os pequenos números sempre põem em risco alguma ideia dos interesses gerais, que se acredita que sejam mais bem servidos quando os indivíduos deliberam com todos os outros indivíduos" (APPADURAI, 2009, p. 53). Segundo ele, espera-se que esses indivíduos, no nosso caso os rolezinhos, negociem a partir de algum mecanismo de representação. E é justamente esse o problema que se dá nas relações sociais na pós-modernidade. A possibilidade de representação se esboroou com a desconfiança em relação ao Poder. Weber, em seu "Ensaio sobre algumas categorias da Sociologia Compreensiva" (1913), percebeu que era possível procurar a constituição de sentido sociológico por meio de atividades humanas - isto é, contra o psicologismo, o historicismo e o realismo. Se no materialismo histórico o que conta são relações objetivas de produção, na tradição compreensiva importa antes as condições reflexivas do agir humano, do agir social, do agir comunitário, incluindo práticas afetivas desse agir. Portanto, não seria coerente com a prática compreensiva observarmos o fenômeno dos rolezinhos apenas como uma manifestação entre o centro e a periferia ou entre o que restou na pós-modernidade da nomenclatura classificatória em classes sociais. Termos como ideologia, status quo, mais-valia e até capitalismo (no sentido de um modelo de sociedade perfeitamente configurada) causam, hoje, estranhamento.

Esta mudança de fundo ideológico aponta para mudanças também na sociedade. Vimos que os rolezinhos se apresentam, na proposta compreensiva, não apenas como agentes portadores de estruturas, mas também como pessoas ativas que sinalizam para um estado de um imaginário. O termo imaginário não é sinônimo de fantasia ou ilusão, mas sim a característica de um trajeto antropológico no qual acontece "uma incessante troca entre as pulsões subjetivas e assimiladoras e as intimações objetivas que emanam do meio cósmico e social", segundo Durand (1997, p. 41). 
Uma maneira de pensar disjuntiva prevalece socialmente na reação aos "rolezinhos". Para além do bem e do mal, é dessa relativização dos polos de que falamos; o institucional, de um lado, e o instituinte, de outro. Primeiramente, seria importante focalizarmos, nos apoiando em Nietzsche, essa questão da dialogia das polaridades, sobretudo quando ele, Nietzsche, refere-se a Sócrates. Nietzsche irá desenvolver, em várias obras, mas aqui destacaríamos especialmente "Genealogia da moral" (1998), a crítica ao que ele denominou "socratismo da moral". "[...] entendeu que o mundo inteiro dele necessitava de seu remédio, seu tratamento, seu artifício pessoal de autopreservação: os instintos querem fazer o papel de tirano; inventa-se um contratirano" (NIETZSCHE, 2006, p. 21). Logo, conclui Nietzsche, Sócrates fez da Razão uma tirania e a racionalidade foi percebida, nas palavras de Nietzsche (2006, p. 21), como salvadora. A má consciência do ideal ascético introduzido desde Sócrates é a purificação de todo obstáculo, na opinião de Nietzsche (1998), o que, neste artigo, é interpretada como uma forma de espírito contemporânea do Instituído e como um imaginário do desmanche.

Nietzsche questionou o valor dos valores morais (1998, p. 12) e chegou ao niilismo (ausência de fundamento, o nada): a visão do homem que agora cansa. O Instituído cansou do homem, isso porque se considera de boa estirpe, enquanto os "rolezinhos", e podemos incluir outras "tribos", são sinônimos de algo menor e ruim, um obstáculo para os planos do Instituído. E, sendo um obstáculo, melhor é ignorá-los, esquecê-los, desprezá-los. Portanto, poderíamos observar os "rolezinhos" dentro de uma tensão das polaridades que se origina, de um lado, da má consciência do Instituído que atribui a si uma superioridade contra um pensamento considerado por ele, Instituído, baixo, imoral e vulgar do Instituinte. As polaridades do "bom" e do "mau" estão presentes na Primeira Dissertação de "Genealogia da moral", de Nietzsche (2006). Trata-se de uma homologia, uma equivalência entre o problema apresentado por Nietzsche e a questão do imaginário dos "rolezinhos". Nesse imaginário dos "rolezinhos" inclui-se, também, a teorização de Maffesoli (2001) sobre nomadismo. Os "rolezinhos", resumidamente, são um exemplo de nomadismo no sentido em que se deslocam constantemente, além de sua imprevisibilidade. Nomadismo, 
nos termos maffesolianos, é a saturação do esquema identitário, o de um gênero bem definido, o de uma ideologia reconhecível, o de uma função profissional fixa, o de uma identidade única como "jovem de periferia". Vestimos máscaras, o que está na raiz etimológica da palavra "pessoa", oriunda de "persona". Somos vários. O Eu é Outro. Para o Instituído, porém, o "rolezinho", que não é só a prática do "rolê" ou "dar uma banda", mas também o epíteto dos jovens que aderem a essa prática, afronta o Poder. O caráter fluido e líquido (nos termos de Bauman, 2001) dos "rolezinhos" gera instabilidade no Instituído e, portanto, medo.

O Instituído é sinônimo de Poder e o Poder acredita no Deus único e no indivíduo indivisível. Já na Potência a força é profunda, vem da base, do húmus. O vitalismo pós-moderno, aquele mesmo observado na prática dos "rolezinhos", é causa de uma forte circulação, que incorpora nesse deslocamento questões de valores, também. Um Mercado Público, por exemplo, é a marca de uma cidade porque, justamente, coloca em movimento uma multiplicidade de elementos, tanto afetivos quanto econômicos, e isso porque o nomadismo, segundo a tese de Maffesoli, despreza as fronteiras e a domesticação, no sentido de apaziguamento. Evitar os "rolezinhos" é uma fantasia do Uno. É o mesmo que recusar a presença do Deus Dionísio, que gera desconforto e desregramento no conjunto social, mas que, por outro lado, transporta uma carga emocional de alta voltagem e, por isso mesmo, restitui a alma do lugar. Sufocar a manifestação dos "rolezinhos" seria expressão de uma "violência totalitária" (Maffesoli, 2001) e de uma agressão racionalista (saber tudo, dominar tudo, esclarecer tudo e subjugar tudo). O que funda o nomadismo, conforme a tese de Maffesoli (2001), é o desejo de evasão. Os "rolezinhos", assim, teriam uma natureza errante e dinâmica nesta pós-modernidade.

A globalização pós-industrial é um problema para as minorias como os "rolezinhos"? O geógrafo Milton Santos acredita em outra globalização. A que está aí, e que inclui o problema dos "rolezinhos", é perversa, na opinião dele (2001). E é perversa, segundo ele, pelo fato de que se observa uma dupla tirania, a do dinheiro e a da informação. Estas duas instâncias, por assim dizer, acabam atingindo, por sua vez, a relação dos atores sociais com a produção e o consumo. 
Essa relação é considerada, por Santos, como um novo ethos, que afeta o caráter das pessoas; por isso, gera competitividade e, por extensão, novos totalitarismos. Qual seria para Milton Santos, então, o modelo de globalização que vingou até hoje? É o "globalitarismo", neologismo de Santos para se referir ao "discurso único no mundo" (2001, p. 38). A publicidade, na opinião dele, é o novo encantamento do mundo, pois propaga-se de tudo. A ideia de aldeia global para Santos, em suma, e nas palavras dele, é uma fábula. Santos também critica a desterritorialização, ou seja, o desfalecimento das fronteiras como imperativo da globalização. Trata-se de outra fábula, segundo ele. Para Milton Santos, a ciência econômica está a serviço do sistema ideológico e o consumo torna-se despótico ao se antecipar ao consumidor pela via da publicidade, que traduz o imaginário pós-moderno.

Legros (2007) observa um impulso desse termo imaginário (em termos sociológicos) a partir dos anos 1960, seguido de um forte crescimento, quase regular. Antes de 1960, segundo ele, foram publicadas apenas algumas obras cujo título contém o grupo nominal "o imaginário", exemplificando com a coleção de poemas de George Hugnet, La hampe de l'imaginaire (1936), dedicada a André Breton; a célebre obra de Sartre, L'imaginaire (1940); o estudo do psicólogo Jean Château sobre Le réel et l'imaginaire dans le jeu de l'enfant (1946) e um texto de Michel Planque, intitulado L'enfant et l'imaginaire (1959). O ano de 1960, portanto, marca o início de uma forte corrente de interesse pelo imaginário, junto com o surgimento da obra de Gilbert Durand (1960). "Naturalmente, este grupo nominal vai cobrir acepções fortemente diferentes segundo os autores: uma instância psíquica em Lacan, uma dimensão da criatividade humana em Caillois, uma mentalidade coletiva entre os historiadores" (LEGROS et alli, 2007, pp. 257-258). Legros repara, também, ao examinar os títulos, que este grupo nominal é raramente utilizado sozinho e que ele é, frequentemente, seguido por termos como o imaginário francês, europeu, ocidental, islâmico, nórdico, cavaleiresco, urbano; o imaginário feudal, medieval, Renascentista, flaubertiano, proustiano; o imaginário amoroso, incestuoso; o imaginário infantil, masculino, feminino; o 
imaginário jurídico, médico, político, cultural. São formas de qualificação do imaginário.

Se atualizarmos a questão dos rolezinhos com uma leitura do imaginário sociológico, veremos, com Maffesoli, que "todo objeto ou fenômeno está ligado a outros, e é determinado por eles. E, por isso mesmo, está sujeito à mudança e ao acaso" (2004, p. 10). Nietzsche dizia do trágico que há "vontade de gerar" (1995, p.93), e é dessa vontade que surge uma "dinâmica da criação". Durand (1997) estabelece, por sua vez, os regimes diurno e noturno do imaginário. É a partir de uma sensibilidade, interagindo com o meio, que se produzem as imagens simbólicas que nos interessam. O símbolo, assim, é, para Durand, a maneira como o imaginário se expressa. O imaginário, na concepção de Durand (2000), seria expresso, portanto, pelo símbolo por meio do que ele chama de uma “convergência simbólica”, isto é, a forma como eles (os símbolos, não-gratuitos e não-arbitrários) se organizam. Por exemplo: símbolos ascensionais (verticalidade, asa, angelismo, soberania uraniana) e cíclicos (lunar). Os símbolos de inversão, ainda, "desdramatizam" o conteúdo angustiante de uma expressão simbólica; e os da intimidade simbolizam, conforme Rocha Pitta (2005, p.3 1), a "justa recompensa de uma vida agitada". A noção de "trajeto antropológico", em Durand, neste breve resumo, seria "uma maneira própria de estabelecer a relação existente entre sua sensibilidade (pulsões subjetivas) e o meio em que vive (tanto o meio físico como histórico e social)" (PITTA, 2005, p. 21).

Sob um ponto de vista sociológico, “[...] o pós-moderno também é fruto de um imaginário que começa a aflorar, de outros mitos que ressurgem, matriciando uma nova bacia semântica”, afirma Maria Cecília S. Teixeira (apud BARROS, 2009, p. 67). Ela diz que o pós-modernismo ganha mais visibilidade por causa de suas manifestações artísticas e arquitetônicas (Maffesoli fala em barroquização do mundo). Sem entrar na discussão sobre pós-moderno, que, para Maria Cecília, é polêmica, o fato é que se vive em uma época de transição que, para alguns teóricos, assume um caráter de complexidade (Morin), simulacro (Baudrillard), liquidez (Bauman) ou tribalismo (Mafesoli). 
Os sujeitos portadores destas reivindicações, ao contrário dos novos ricos de antigamente, exaltam suas raízes. Sua inclusão social é feita através do consumo midiatizado, participante do processo de ficcionalização da vida referido por Augé. Ele credita à mídia o poder de agenciar imaginários. Mas o imaginário não agencia nada, porque é de natureza "alógica". Seria mesmo possível agenciar imaginários? Qual é, afinal, o panorama destes imaginários, sua relação com os desejos (de consumo, de afirmação) e com as implicações sociopolíticas? A afirmação do eu em estilos próprios e marcadamente distintivos seja a principal emergência dos jovens dessa pós-periferia? Então, o que se busca não é a igualdade, e sim a diferença. Os desejos agenciados pela mídia com objetivos comerciais eficazmente canalizados pelos processos de inclusão social através do consumo tiveram como efeito colateral a emergência do que as autoras vêm chamando de pós-periferia. Mas tanto os desejos agenciados quanto a reivindicação de consumo, lazer e entretenimento e toda a gama de reações sociopolíticas que vêm acompanhando essas adequadamente nomeadas diásporas constituem não um imaginário, e sim sintomas de um imaginário que ainda não conseguimos equacionar adequadamente. Para que avancemos no delineamento desse imaginário, é necessário especular sobre as pulsões antropológicas que estão sendo tensionadas pelas coerções sociais constituídas pelos fenômenos ligados à pós-periferia.

Ao distinguirmos desejos de necessidades, distinguimos também pulsões de instintos. Enquanto o instinto tem objeto biológico definido, a pulsão não tem e por esse motivo é insaciável. Esta ausência de objeto biológico é constituinte da heterogeneidade da experiência humana. Tentar saciar o desejo é buscar o prazer, mas o prazer fica dentro de certos limites para não causar dor. É aí que Lacan encontra a teoria de Freud sobre a pulsão de morte, que vai "além do princípio de prazer", para falar do gozo. O gozo se filia à pulsão de morte porque transborda os limites, quebra as regras. (E uma das expressões da pulsão de morte, disse Freud, é a compulsão pela repetição, tão presente no consumo.) A transgressão está na natureza mesma do gozo.

No entanto, enquanto em Freud é impossível harmonizar a pulsão com a cultura e o conflito é resolvido por meio das proibições que, se transgredidas, 
levam ao gozo e à morte, Durand (1997) postula que a compatibilização destes dois polos nas sociedades ocorre sim, e ocorre através da formação do imaginário. Este imaginário pode, naturalmente, abrigar múltiplos imaginários, mas todos eles participam de uma mesma dinâmica, movem-se num trajeto entre pulsões antropológicas e coerções sociais, culturais, históricas... O que é importante reter nesse momento é o caráter de acordo e não de conflito reprimido entre as pulsões e as coerções. Os desejos que movem a pós-periferia para os espaços ocupados pelos que antes estavam no centro são os mesmos que levam estes últimos atores a repelirem os recém-chegados. No polo das coerções há mais variação na formação destes dois imaginários, mas talvez o acordo tenha se dado através de uma mesma grande imagem: o desejo de diferença. Designemos como protoincluídos os burgueses (nos termos marxistas, sem referendarmos totalmente essa visão) que chegaram bem antes ao espaço privilegiado do consumo. Para eles, esse desejo realizado traz apenas o prazer; são os neoincluídos que realmente gozam com ele, pois o surgimento da pósperiferia é uma transgressão no sentido de abalar um cenário estabelecido.

Os neoincluídos, antes mergulhados na indiferenciação de uma periferia, receberam da história as ferramentas para trabalharem seu desejo de distinção. Grosso modo, essas ferramentas são a maior capacidade de consumo e a conectividade. Para chegar à diferença, é necessário o corte, a ruptura. Então podemos avançar que o regime de imagens desse fenômeno é diairético, busca a separação. Os protoincluídos buscaram em cada momento uma distinção levemente variada: num momento inicial, talvez a ostentação material característica da estética kitsch do início do século 20, resolvida simplistamente pelo "tenho algo que nem todos podem ter e isso faz de mim uma pessoa especial"; ao longo do tempo, estes que àquela altura eram os recém-chegados perceberam certa falta de diálogo cultural com os que já estavam lá e procuraram assim uma identidade intelectual, por vários meios. (No Brasil, os fotoclubes tiveram um papel importante nessa busca de estofo cultural dos novos ricos.) Havia certa vergonha das raízes, vergonha que talvez tenha prosseguido gerações afora e chegado aos dias de hoje, podendo ser observada sutilmente nas manifestações contra a Copa que sublinham a inadequação do 
Brasil para sediar um evento mundial, mas cujo paroxismo está nas reações escandalizadas ao compartilhamento necessário de espaços conquistados com os neoincluídos, visível nas comparações de aeroportos a rodoviárias (antes, só os bem de vida podiam viajar de avião) ou nos lamentos de socialites por não poderem mais se exibir com os perfumes comprados diretamente em Paris, já que os mesmos frascos são facilmente encontráveis aqui no Brasil mesmo ou, pior ainda na visão delas, nas lojas de Paris os cidadãos brasileiros são facilmente encontráveis.

Ora, enquanto os protoincluídos continuam com o mesmo comportamento de rejeitar as raízes, os neoincluídos, pelo contrário, têm orgulho delas. Assim, os protoincluídos não apenas receiam que seu espaço se transforme em outra coisa por causa da presença dos recém-chegados como também rejeitam nestes recém-chegados sua própria imagem de outrora. Se quisermos falar de imagens arquetípicas, estamos vendo uma luta de ego e sombra. Se preferimos nos reportar aos schèmes durandianos, teremos o schème dierético, a pulsão pela separação que pode se dar tanto através das purificações rituais quanto pelas armas. Os neoincluídos exaltam o lugar de onde vieram, mas ambicionam os mesmos espaços privilegiados dos protoincluídos. Entre a pulsão do consumo e a coerção identitária, a imagem da cisão resolve o conflito. Ao contrário do que certa mídia quis afirmar, os protagonistas da pós-periferia não são traídos na sua vontade de se parecerem com a burguesia por andarem em bando e usarem itens falsificados; estes comportamentos informam seu desejo de se distinguirem dos protoincluídos. $\mathrm{E}$ se eles frequentam o shopping center não é apenas por causa do ar condicionado grátis, mas também porque é lá que a burguesia vai vê-los, é lá que será possível evidenciar seu orgulho de ter nascido na favela; sem exibir sua neoinclusão, não seria possível avançar sobre os limites do prazer para finalmente gozar.

Se diagnósticos neste cenário mutante são temíveis, mais duvidosos ainda são os prognósticos. Tendo em conta a dinamização da sociedade através dos mitos circulantes no imaginário que foram apresentados por Durand (1997) através do conceito de tópica sociocultural, é possível especular sobre os 
caminhos que se abrem para a sociedade brasileira sob este aspecto. Se a pósperiferia se confirmar como uma eclosão de algo que vinha sendo reprimido, teremos realmente uma mudança de mito diretor, uma nova axiomática ocupando pouco a pouco os espaços institucionalizados e por aí perdendo também sua potência transgressora. Mas também é possível que este mito que se manifesta agora não seja realmente diferente daquele que já está no comando, mas apenas uma nova usura de um de seus aspectos. A axiomática vai continuar, então, a mesma por mais algum tempo.

De quais mitos estamos falando? Impossível diagnosticá-los sem um recorte empírico aprofundado no tempo e no espaço e sem uma rigorosa construção mitanalítica que indique não apenas qual mito preside nosso tempo, mas sobretudo quais dos seus aspectos foram reprimidos ou hiperbolizados. Este processo de usura e degradação do mito é uma exigência do tempo histórico, mas também é responsável pelo desequilíbrio do imaginário e pela consequente busca de reequilíbrio à toda força, quando os efeitos nefastos se tornam incontornáveis.

Não estaríamos presenciando, neste que poderíamos chamar de "imaginário do desmanche" (COELHO, 1995), uma espécie de nova moralidade? "Nova moralidade" que é difícil de se aceitar por parte dos chamados protoincluídos, aqui representantes de um ego social contrário aos grupos marginalizados dentre os quais se encontram, agora, os jovens de periferia (neoincluídos)? Essa "nova moralidade", portanto, romperia com a maneira tradicional de agir e avaliar, se tomarmos a moralidade como uma obediência aos costumes. Trata-se, da parte dos neoincluídos, de uma afirmação de si, isso porque confronta o periférico ao instituído.

A tradição é questionada. É um movimento subterrâneo. É uma desobediência à imposição de um estatuto de diferenciação societal (em termos maffesolianos, aquilo que se desdobra organicamente, neste caso tanto da parte dos proto quanto dos neoincluídos). Ou seja, tanto é natural aos protoincluídos a diferenciação pelo consumo quanto a dos neoincluídos pela presença no templo consumista antes acessível apenas aos abastados. Nunca uma autoridade 
quis ser tomada por objeto de crítica. E a atitude dos neoincluídos não deixa de expor uma crítica, mesmo que não inversamente proporcional ao consumo, isso porque também consumir não é o ato de rebeldia dos neoincluídos, e sim o contrário: não fazê-lo no espaço desse mesmo consumo. Percebe-se um rompimento com a tradição porque não mais interessa aquilo que se faz porque se ordena, aquilo que põe em ordem ou que se faz intimidar moralmente. A pósperiferia não mais se intimida e não mais obedece porque se quer algum ordenamento. Vale aquilo que vem da vontade de si, sem a observância de algum tipo de prescrição. Sob o manto da moralidade dos protoincluídos, toda forma de originalidade dos neoincluídos transforma-se em má consciência.

Os "rolezinhos" são os "terceiros incluídos". Essa inclusão, tomando por analogia as estruturas polarizantes em Durand (2003), implica "uma dinâmica de orientação das forças". Isso porque, de acordo com ele, "[...] a homogeneização subentendida por uma heterogeneização constitutiva é a noção que nos sugere a polaridade" (2003, p. 117). E não só na antropologia, como salienta Durand (2003), mas também na Física (atômica), na História (das religiões) e na Teosofia (mística). A tessitura das ações sociais, finalizando, é um complexo jogo de múltiplas linhas de força. A ação econômica, apenas, que foi o baluarte da teoria marxista, não é determinante na pós-modenidade. Weber já deixava isso claro na sua Teoria da Ação Social e, mesmo para procurar as origens do capitalismo, foi buscá-las não na Economia, mas na ética protestante. A relação entre o capital herdado e a participação dos protestantes na propriedade do capital "não se entrega de forma tão indubitável" (WEBER, 2004). A relação de causalidade entre "rolezinho" e "marginalidade" não é, seguindo o exemplo weberiano em relação ao capitalismo, tão pacífica. $\mathrm{O}$ "rolezinho" se inscreve antes no dinamismo, para além de uma estática, de uma pós-modernidade complexa (palavra-problema) e, muitas vezes, alógica.

\section{Referências}

APPADURAI, A. O medo ao pequeno número. São Paulo: Iluminuras, 2009.

BARROS, E.P. O cinema de Ruy Guerra: um imaginário autoral na pósmodernidade. Porto Alegre, 2009. Tese (Doutorado em Comunicação 
Social), Pontifícia Universidade Católica do Rio Grande do Sul (PUCRS), 2009.

BAUMAN, Z. Modernidade líquida. Rio de Janeiro: Zahar, 2001.

COElHo, T. Dicionário crítico de Políticas Culturais. Cultura e imaginário. São Paulo: Iluminuras, 1997.

COELHO, T. Moderno pós moderno. Modos \& versões. São Paulo: Iluminuras, 1995.

DURAND, G. As estruturas antropológicas do imaginário. Introdução à arquetipologia geral. São Paulo: Martins Fontes, 1997.

DURAND, G. O imaginário. Ensaio acerca das ciências e da filosofia da imagem. Rio de Janeiro: Difel, 1998.

DURAND, G. A imaginação simbólica. Lisboa: Edições 70, 2000)

DURAND, G. Mito, símbolo e mitodologia. Lisboa: Editorial Presença, 1981.

DURAND, G. Structures. Éranos I. Paris: Éditions La Table Ronde, 2003.

FREUD, S. Além do princípio de prazer. Rio de Janeiro: Imago, 1998.

LACAN, J. O seminário. Livro 07: a ética da Psicanálise. Rio de Janeiro: Jorge Zahar,1991.

MAFFESOLI, M. Sobre o nomadismo. Vagabundagens pós-modernas. Rio de Janeiro: Record, 2001.

MAFFESOLI, M. A violência totalitária. Ensaio de antropologia política. Porto Alegre: Sulina, 2001.

MAFFESOLI, M. O tempo das tribos. Rio de Janeiro: Forense Universitária, 1997.

MAFFESOLI, M. Homo eroticus. Des communions émotionnelles. Paris: CNRS, 2012.

MORIN, E. Introdução ao pensamento complexo. Lisboa: Instituto Piaget, 1991.

NIETZSCHE, F. A origem da tragédia. Lisboa: Guimarães Editores, 2002.

NIETZSCHE, F. Crepúsculo dos ídolos. Como se filosofa com o martelo. São Paulo: Companhia das Letras, 2006.

NIETZSCHE, F. Genealogia da moral. Uma polêmica. São Paulo: Companhia das Letras, 1998.

NIETZSCHE, F. Aurora. São Paulo: Escala, 2007.

PEREIRA, S.L.; ROCHA, Rose de Melo.; SILVA, J.C. Imaginários de uma outra diáspora: consumo, urbanidade e acontecimentos pósperiféricos. XII COMPÓS, Belém, 2014. Anais. Disponível em www.compos.org.br/biblioteca.php. Consultado em 17/mai/2015. 
PITTA, D.R. Introdução à teoria do imaginário de Gilbert Durand. Rio de Janeiro: Atlântica, 2005.

ROLEZEIROS gastam R\$1.00o em Mizuno; classe A rejeita itens popularizados. UOL, 3/02/2014. Disponível em http://economia.uol.com.br/noticias/redacao/2014/o2/o3/rolezeirosgastam-r-1000-em-mizuno-classe-a-rejeita-itens-popularizados.htm.

SANTOS, M. Por uma outra globalização. Rio de Janeiro: Record, 2001.

SIMMEL, G. Questões fundamentais de sociologia. Rio de Janeiro: Zahar, 2006.

WEBER, M. A ética protestante e o "espírito" do capitalismo. São Paulo: Companhia das Letras, 2004. 